\title{
Efficiency of different PCR-based marker systems for assessment of Iris pumila genetic diversity
}

\section{Bublyk, Olena M.}

2013-08

Bublyk , O M , Andreev , I O , Kalendar, R , Spiridonova, K V \& Kunakh , V A 2013 , ' Efficiency of different PCR-based marker systems for assessment of Iris pumila genetic diversity ' , Biologia (Bratislava) , vol. 68 , no. 4 , pp. 613-620 . https://doi.org/10.2478/s11756-013-0192-4

http://hdl.handle.net/10138/42940

https://doi.org/10.2478/s11756-013-0192-4

cc_by_nc_nd

publishedVersion

Downloaded from Helda, University of Helsinki institutional repository.

This is an electronic reprint of the original article.

This reprint may differ from the original in pagination and typographic detail.

Please cite the original version. 


\title{
Efficiency of different PCR-based marker systems for assessment of Iris pumila genetic diversity
}

\author{
Olena M. Bublyk ${ }^{1}$, Igor O. Andreev ${ }^{1}$, Ruslan N. Kalendar ${ }^{2}$, Kateryna V. Spiridonova ${ }^{1}$ \\ \& Viktor A. KUnAKH ${ }^{1}$ \\ ${ }^{1}$ Institute of Molecular Biology and Genetics NAS of Ukraine, 150, Zabolotnogo Str., 03680 Kyiv, Ukraine; e-mail: \\ o.m.bublyk@imbg.org.ua \\ ${ }^{2}$ MTT/BI Plant Genomics, Institute of Biotechnology, University of Helsinki, P.O. Box 65, FIN-00014 Helsinki, Finland
}

\begin{abstract}
We investigated informativeness and effectiveness of different marker types (ISSR, IRAP, REMAP, RGAP and LP-PCR that employ primers based on the conservative sequences of abiotic stress response genes) to study genetic diversity of Iris pumila L. By the number of amplicons per primer, number of polymorphic amplicons per primer and resolving power index (Rp), ISSR-markers were the most efficient followed by LP-PCR-markers. In order of decreasing value of indicators of genetic diversity "the percentage of polymorphic bands", and "the average Jaccard's genetic distance between plants", marker systems may be arranged as follows: ISSR $>$ RAPD $>$ LP-PC $>$ RGAP $\approx$ IRAP. For ISSR-markers, the percentage of polymorphic bands was 1.3-1.7 times higher than for the others, and the average genetic distance was 1.2-1.3 times higher. Different marker systems were ranked by the value of Nei's gene diversity and the Shannon's index as follows: ISSR $>$ RAPD $\approx$ LP-PCR $>$ RGAP $\approx$ IRAP, with the highest and the lowest values differing 1.4 times. Genetic population structure was investigated with program Structure 2.3. The data of all marker systems suggest that all genomes under study belonged to one population. The PCoA and cluster analyses based on genetic distances showed distinctions in clustering generated from different markers data and summarized data, as well as the lack of strong clusters. Mantel test revealed significant positive correlation between the matrices of genetic distances generated by the data of almost all marker systems. The strongest correlation was found between RGAP- and IRAP-markers $(r=0.452, p=0.01)$ and between RGAP and ISSR $(r=0.430, p=0.01)$. ISSR, RAPD and LP-PCR proved to be more effective for the study of $I$. pumila genetic diversity, nevertheless, joint use of different marker systems will provide a more comprehensive assessment of variation in different genomic regions.
\end{abstract}

Key words: endangered plant species; genetic diversity; indices of genetic diversity; Iris pumila L.; molecular genetic analysis; natural populations; PCR-based marker systems

Abbreviations: CTAB, cetyl trimethylammonium bromide; IRAP, Inter-Retrotransposon Amplified Polymorphism; ISSR, Inter-Simple Sequence Repeat; LP-PCR, Long Primer PCR; NJ, Neighbor Joining; PCoA, principal coordinate analysis; PCR, polymerase chain reaction; RAPD, Random Amplified Polymorphic DNA; REMAP, Retrotransposon-Microsatellite Amplified Polymorphism; RGAP, Resistance Gene Analog Polymorphisms

\section{Introduction}

Nowadays, the assessment of genetic diversity within and between populations is often performed by the use of various PCR-derived markers based on non-coding DNA regions (Kalendar \& Glazko 2002) as well as various genes (Gupta \& Rustgi 2004) and retrotransposons (Kalendar 2011; Mondini et al. 2009). The choice of technique and proper markers is one of the important steps in population genetic analysis. The rate of evolutionary changes for particular genomic regions that seems to predetermine the level of phylogenetic resolving capacity may differ for various organisms. Therefore every new group of organisms requires a distinctive approach and analysis of various genomic areas as potential molecular genetic markers (Biswas et al. 2010).
In this study we compared common PCR-based marker systems, such as RAPD, ISSR, IRAP, REMAP, and relatively new ones, RGAP and LP-PCR, by their ability to detect the genetic polymorphism. These techniques are practically simple; don't require information on DNA sequence; due to high sensitivity, allow using low DNA amount as a template for amplification that is of special importance for rare species. RAPD-PCR allows studying polymorphism of anonymous sequences showing various copy number to be scattered all over the genome. ISSR-PCR covers genomic areas flanked with inverted repeats of satellite loci. Both of them acquired a reputation as efficient and low-cost techniques for genetic analysis. RAPDand ISSR-markers are thought to represent preferentially non-coding DNA regions to be selectively neutral, 
although there is evidence that RAPD-markers may be associated with functionally important loci (Penner 1996). Two types of the applied markers based on mobile genetic elements are IRAP and REMAP. IRAP uses one or two primers specific for long terminal repeat (LTR) sequences, while REMAP is similar to IRAP, but one of the two primers matches a microsatellite motif. The effectiveness of these markers is resulted from the abundance of retroelements within genomes of majority plants and their ability to produce new copies. These markers are simple in estimation and low-cost but show higher reproducibility as compared with RAPD and ISSR due to longer primers (Biswas et al. 2010). IRAP and REMAP have been widely used for the analysis of genetic diversity and structure of plant populations and successfully applied for a great number of species (Kalendar 2011). For this study, we also used RGAP and LP-PCR to employ markers based on the conservative sequences of disease resistance genes and abiotic stress response genes, respectively. RGAP- and LPPCR-primers were developed on the basis of the genes belonging to multigene families; therefore they produced highly polymorphic patterns with great number of anonymous fragments containing mainly coding sequences (Dong et al. 2009; Liviero et al. 2002). The function of the above mentioned genes is directly related to ensuring organism viability in stress environment; therefore their variability may be of adaptive significance.

Dwarf bearded iris, Iris pumila L. (Iridaceae), is a herbaceous perennial clonal monocot with hermaphroditic enthomophylous flowers. This plant is of great ornamental value and is used in flower breeding (Sikura \& Shysha 2010). As a result of injurious effects of human activity and natural factors the number of dwarf iris is steadily declining, there occur intensive destruction and fragmentation of its natural habitats. I. pumila is protected over the territories of several regions in Ukraine (Parnikoza et al. 2011). It needs to determine the level of genetic variation, examine the genetic processes in populations, and in the long run, to develop the scientifically substantiated approaches to the species conservation and exploitation. As far as it is known, there are no molecular genetic investigations concerning the state of I. pumila gene pool to date.

The objective of the study was to compare the various types of molecular genetic markers, namely RAPD, ISSR, IRAP, REMAP, RGAP and LP-PCR, by their efficiency to evaluate the genetic diversity of $I$. pumila as well as to analyse population genetic structure.

\section{Material and methods}

The material for the studies, eleven I. pumila plants, was collected from natural population growing near the village Mygiia (Pervomaisk district of Mykolayiv region, Ukraine) from the area of about $100 \mathrm{~m}^{2}$, the distances between the plants varied from 0.5 to $15 \mathrm{~m}$. The sample group included big generative plants as well as juvenile individuals of generative and pre-generative age, distributed preferentially along the edge of the locality. The locality is a part of a larger population comprising more than 1,000 individuals that grow along the upper part of gully slopes over a small stream flowing into the Southern Bug.

DNA was isolated from dried leaves with the CTAB method according to Doyle \& Doyle (1987). PCR was performed in $20 \mu \mathrm{L}$ mixture containing approximately $20 \mathrm{ng}$ DNA, $0.2 \mathrm{mM}$ dNTP, $1.25 \mathrm{U}$ Taq-polymerase, $1 \times$ PCR buffer with $\left(\mathrm{NH}_{4}\right)_{2} \mathrm{SO}_{4}$ (Termo Fisher Scientific, Fermentas, Lithuania), $2 \mathrm{mM} \mathrm{MgCl}_{2}, 0.5 \mu \mathrm{M}$ IRAP, or $0.6 \mu \mathrm{M}$ RAPD, or $1 \mu \mathrm{M}$ of ISSR, RGAP and LP-PCR primers (if primers were used in pair $-0.5 \mu \mathrm{M}$ each). The reaction mixture was layered by $15 \mu \mathrm{L}$ of mineral oil to prevent evaporation. As a negative control the standard reaction mixture without DNA was used. Reactions were performed in Tertsyk MC2 thermocycler (Biotechnology, Russia) with the following settings. RAPD: 2 min at $95^{\circ} \mathrm{C}$ for initial denaturation; 5 cycles of $30 \mathrm{~s}$ at $94^{\circ} \mathrm{C}, 30 \mathrm{~s}$ at $36^{\circ} \mathrm{C}, 1 \mathrm{~min}$ at $72^{\circ} \mathrm{C} ; 35$ cycles of $20 \mathrm{~s}$ at $94^{\circ} \mathrm{C}, 20 \mathrm{~s}$ at $36^{\circ} \mathrm{C}, 40 \mathrm{~s}$ at $72^{\circ} \mathrm{C}$; followed by a final extension for $2 \mathrm{~min}$ at $72^{\circ} \mathrm{C}$. ISSR and IRAP: 2 min at $95^{\circ} \mathrm{C} /$ for initial denaturation; 35 cycles of $30 \mathrm{~s}$ at $94^{\circ} \mathrm{C}, 30 \mathrm{~s}$ at optimal temperature of annealing $\left(\mathrm{T}_{\mathrm{a}}\right), 90 \mathrm{~s}$ at $72^{\circ} \mathrm{C}$; final extension for $2 \mathrm{~min}$ at $72^{\circ} \mathrm{C}$, where $\mathrm{T}_{\mathrm{a}}$ were $53^{\circ} \mathrm{C}$ and $58^{\circ} \mathrm{C}$ for ISSR and IRAP primers respectively. RGAP, LP-PCR and REMAP: 2 min at $94^{\circ} \mathrm{C}, 35$ cycles of $30 \mathrm{~s}$ at $94^{\circ} \mathrm{C}, 30 \mathrm{~s}$ at $\mathrm{T}_{\mathrm{a}}, 90 \mathrm{~s}$ at $72^{\circ} \mathrm{C} ; 2 \mathrm{~min} 30 \mathrm{~s}$ at $72^{\circ} \mathrm{C}$. $\mathrm{T}_{\mathrm{a}}$ was $45^{\circ} \mathrm{C}$ for RGAP-primers and $55^{\circ} \mathrm{C}$ for LP-PCR and REMAP-primers.

Amplification products were separated on $1.5 \%$ agarose gel in $0.5 \times$ TBE buffer and stained with ethidium bromide.

Each reaction was performed in two replicates, only clear reproducible bands were scored. Amplification products detected on the gels were recorded as binary matrix in which presence or absence of fragments of similar size was represented as " 1 " or " 0 ". Based on the binary matrices Jaccard's genetic distances between plants were calculated and principal coordinate analysis (PCoA) was performed with the program FAMD ver.1.25 (Schluter \& Harris 2006). NJ trees with 1000 bootstrap replicates were constructed using FAMD and the extended majority rule consensus trees were inferred using program Consense from the Phylip package (Felsenstein 2004) for each marker set and total data.

To estimate the level of genetic polymorphism, the percentage of polymorphic amplicons (P), Shannon's index (S), Nei's gene diversity (the expected heterozygosity $\mathrm{He}$ ) were calculated with the program GenAlEx ver.6.4 (Peakall \& Smouse 2006). Mantel test with 999 permutations (Mantel 1967) was also performed in GenAlEx to assess the correlation between matrices of genetic distances obtained from the different markers as well as that between the matrix of genetic distances calculated for the total data and the matrix of geographic distances between sites of plant collection. The resolving capacity of primers (Rp) was determined according to Prevost \& Wilkinson (1999) as $\mathrm{Rp}=\sum \mathrm{I}_{\mathrm{b}}$, where $\mathrm{I}_{\mathrm{b}}$ (band informativeness) $=1-(2 \times|0.5-p|)$, and $p$ is the proportion of genotypes in samples containing the band.

Genetic population structure was investigated with program Structure 2.3.4 (Falush et al. 2003; Pritchard et al. 2000) adapted to dominant markers. Analyses were carried out under the admixture model assuming correlated allele frequencies. To determine the most likely number of groups $(\mathrm{K})$ in the data, a series of analyses were performed from $K=1$ through 11, using 50,000 burn-in and 100,000 repetitions, with 20 iterations per $K$. 
Table 1. Nucleotide sequences and characteristics of primers chosen for I. pumila polymorphism study.

\begin{tabular}{|c|c|c|c|c|c|c|c|}
\hline \multirow{2}{*}{$\begin{array}{l}\text { Marker } \\
\text { system }\end{array}$} & \multirow{2}{*}{ No. } & \multirow{2}{*}{ Primer } & \multirow{2}{*}{ Nucleotide sequence $\left(5^{\prime}-3^{\prime}\right)$} & \multicolumn{2}{|c|}{ Number of amplicons } & \multirow{2}{*}{$\begin{array}{l}\text { Resolbving } \\
\text { power ( } \mathrm{Rp})\end{array}$} & \multirow{2}{*}{ Primer source } \\
\hline & & & & total & polymorphic & & \\
\hline \multirow[t]{9}{*}{ RAPD } & 1 & $\mathrm{~A} 07$ & GAAACGGGTG & 17 & 13 & 5.27 & \multirow{9}{*}{$\begin{array}{c}\text { Operon Technologies, } \\
\text { Inc. (Alameda, CA) }\end{array}$} \\
\hline & 2 & A08 & GTGACGTAGG & 17 & 16 & 8.98 & \\
\hline & 3 & A12 & TCGGCGATAG & 11 & 9 & 3.64 & \\
\hline & 4 & A16 & AGCCAGCGAA & 12 & 7 & 2.91 & \\
\hline & 5 & $\mathrm{~A} 17$ & GACCGCTTGT & 11 & 8 & 5.82 & \\
\hline & 6 & A19 & CAAACGTCGG & 11 & 8 & 4.36 & \\
\hline & 7 & B01 & GTTTCGCTCC & 10 & 6 & 3.09 & \\
\hline & 8 & B05 & TGCGCCCTTC & 13 & 12 & 5.09 & \\
\hline & 9 & B08 & GTCCACACGG & 13 & 10 & 5.64 & \\
\hline \multirow[t]{8}{*}{ ISSR } & 1 & ISSR-03 & $(\mathrm{AC})_{8} \mathrm{TT}$ & 16 & 14 & 5.82 & \multirow{8}{*}{$\begin{array}{l}\text { Biotechnology } \\
\text { Laboratory, The } \\
\text { University of British } \\
\text { Columbia, Canada }\end{array}$} \\
\hline & 2 & ISSR-05 & $(\mathrm{AC})_{8} \mathrm{TG}$ & 8 & 6 & 3.45 & \\
\hline & 3 & ISSR-59 & $(\mathrm{AG})_{8} \mathrm{GC}$ & 17 & 15 & 8.55 & \\
\hline & 4 & UBC\#810 & $(\mathrm{GA})_{8} \mathrm{~T}$ & 21 & 20 & 9.82 & \\
\hline & 5 & UBC \#811 & $(\mathrm{GA})_{8} \mathrm{C}$ & 37 & 36 & 15.27 & \\
\hline & 6 & UBC \#835 & $(\mathrm{AG})_{8} \mathrm{YC}$ & 22 & 20 & 6.91 & \\
\hline & 7 & UBC \#836 & $(\mathrm{AG})_{8} \mathrm{YA}$ & 11 & 9 & 4.36 & \\
\hline & 8 & UBC \#840 & $(\mathrm{GA})_{8} \mathrm{YT}$ & 32 & 30 & 15.09 & \\
\hline \multirow[t]{11}{*}{ RGAP } & 1 & Pto kin3 & TACTTCGGACGTTTACAT & & 11 & & \multirow[t]{11}{*}{ Dong et al. 2009} \\
\hline & 1 & Pto kin4 & AGTGTCTTGTAGGGTATC & 13 & 11 & 5.09 & \\
\hline & 2 & XLRR for & CCGTTGGACAGGAAGGAG & 11 & 4 & 182 & \\
\hline & & XLRR rev & CCCATAGACCGGACTGTT & 11 & & & \\
\hline & 3 & $\begin{array}{l}\text { NLRR for } \\
\text { NLRR rev }\end{array}$ & $\begin{array}{l}\text { TAGGGCCTCTTGCATCGT } \\
\text { TATAAAAAGTGCCGGACT }\end{array}$ & 18 & 16 & 6.18 & \\
\hline & 4 & Cre3Ploop & GCGGGTCTGGGAAATCTACC & 13 & 8 & 300 & \\
\hline & 4 & Cre3-k3 & CTGCAGTAAGCAAAGCAACG & 13 & 8 & 3.09 & \\
\hline & 5 & NLRR-INV1 & TGCTACGTTCTCCGGG & 16 & 13 & 418 & \\
\hline & 5 & NLRR-INV2 & TCAGGCCGTGAAAAATAT & & & 4.18 & \\
\hline & 6 & Pto-kin1 IN1 & AAGTGGAACAAGGTTAGG & 10 & 5 & 218 & \\
\hline & & Pto-kin2 IN2 & GATGCACCACCAGGGGG & & & & \\
\hline \multirow[t]{4}{*}{ LP-PCR } & 1 & MRE & ATGCTATTCTGGAAACGGCC & 21 & 18 & 9.82 & \multirow[t]{4}{*}{ Liviero et al. 2002} \\
\hline & 2 & SGER & TGGTGCGCTCGCCGCTGACG & 21 & 16 & 8.91 & \\
\hline & 3 & 3'HSR & CATTCAGCTCATCGATCCACC & 13 & 6 & 2.36 & \\
\hline & 4 & QQG & ATCCCGGTGTGGCCTTGCTGC & 20 & 15 & 6.73 & \\
\hline \multirow[t]{9}{*}{ IRAP } & 1 & $\begin{array}{l}675 \text { (Calypso LTR, } \\
\text { Glycine } \max \text { ) }\end{array}$ & AGCGCGCGTGCTGGGCTGGG & 13 & 6 & 1.82 & \multirow{9}{*}{$\begin{array}{c}\text { Primers are designed } \\
\text { by Kalendar R.N., } \\
\text { MTT/BI Plant } \\
\text { Genomics, Institute of } \\
\text { Biotechnology, } \\
\text { University of Helsinki }\end{array}$} \\
\hline & 2 & 696 (Cassandra & CGGGGTGGGTCGGGGTGTTAC & 9 & 8 & 3.45 & \\
\hline & & $\begin{array}{l}\text { LTR, Phleum } \\
\text { pratense) }\end{array}$ & & & & & \\
\hline & 3 & $\begin{array}{l}719 \text { (Sukkula LTR, } \\
\text { Hordeum vulgare) }\end{array}$ & TGTGACACCCCGAGACCGATGCG & 22 & 14 & 6.36 & \\
\hline & 4 & $\begin{array}{c}1681 \\
\text { (Brachypodium } \\
\text { distachyon) }\end{array}$ & ATACCTCGGAGGCGCTGCACCTG & 18 & 12 & 4.18 & \\
\hline & 5 & $\begin{array}{c}1686 \\
\text { (B. distachyon) }\end{array}$ & TGGCATCTGCCGTGACACCACCA & 8 & 2 & 1.09 & \\
\hline & 6 & $\begin{array}{c}1687 \\
\text { (B. distachyon) }\end{array}$ & TGGTGGTGTCACGGCAGATGCCA & 14 & 12 & 4.73 & \\
\hline & 7 & $\begin{array}{l}656 \text { (Opie-L, A } \\
\text { Zea mays) }\end{array}$ & \multirow{2}{*}{\multicolumn{2}{|c|}{ AGCACTTGTGTTTGCACTCAATCACC 18}} & 17 & 8.55 & \\
\hline & & $\begin{array}{l}657 \text { (Opie- } \mathrm{R}, \\
\quad \text { Z. mays) }\end{array}$ & & & & & \\
\hline
\end{tabular}

\section{Results}

Initial primer screening was performed on one of the I. pumila plants. Primer was considered as suitable for future studies when it provided amplification of a pattern with more than five clear reproducible fragments.
After the primary screening 14 RAPD-primers from 27 (52\%), 9 from 24 ISSR-primers (38\%), six from eight pairs of RGAP-primers (75\%), four from 13 LP-PCRprimers $(31 \%)$, and 16 from 21 IRAP-primers $(76 \%)$ were chosen for further assessment. Higher universality of RGAP- and IRAP primers is apparently due to the 
Table 2. Summary of information on use of various types of PCR-based markers for I. pumila analysis.

\begin{tabular}{|c|c|c|c|c|c|c|}
\hline $\begin{array}{l}\text { Marker } \\
\text { system }\end{array}$ & $\begin{array}{l}\text { Number of primers/ } \\
\text { primer pairs used }\end{array}$ & $\begin{array}{c}\text { Number of } \\
\text { scored bands }\end{array}$ & $\begin{array}{l}\text { Average number of } \\
\text { bands per primer }\end{array}$ & $\begin{array}{c}\text { Number of } \\
\text { polymorphic bands }\end{array}$ & $\begin{array}{l}\text { Average number of } \\
\text { polymorphic bands } \\
\text { per primer }\end{array}$ & $\begin{array}{l}\text { Average resolving } \\
\text { power }(\mathrm{Rp})\end{array}$ \\
\hline RAPD & 9 & 115 & 12.8 & 89 & 9.9 & 4.98 \\
\hline ISSR & 8 & 164 & 20.5 & 150 & 18.8 & 8.66 \\
\hline RGAP & 6 & 81 & 13.5 & 56 & 9.3 & 3.76 \\
\hline LP-PCR & 4 & 75 & 18.8 & 55 & 13.8 & 6.96 \\
\hline IRAP & 7 & 102 & 14.6 & 71 & 10.1 & 4.31 \\
\hline Total data & 34 & 537 & 15.8 & 421 & 12.4 & 5.72 \\
\hline
\end{tabular}

Table 3. The characteristics of genetic diversity within I. pumila population using various PCR-based marker systems.

\begin{tabular}{|c|c|c|c|c|c|}
\hline Marker system & $\begin{array}{c}\text { Percentage of } \\
\text { polymorphic bands } \\
(\mathrm{P}), \%\end{array}$ & $\begin{array}{l}\text { Nei's gene diversity } \\
\quad(\text { expected } \\
\left.\text { heterozigosity } \mathrm{H}_{\mathrm{e}}\right)\end{array}$ & $\begin{array}{c}\text { Shannon's } \\
\text { information index }(\mathrm{S})\end{array}$ & $\begin{array}{l}\text { Range of Jaccard's } \\
\text { genetic distances } \\
\text { between plants } \\
\left(\mathrm{D}_{\mathrm{j}}\right), \%\end{array}$ & $\begin{array}{l}\text { Average Jaccard's } \\
\text { genetic distance } \\
\text { between plants } \\
\left(\mathrm{D}_{\mathrm{j}}\right), \%\end{array}$ \\
\hline RAPD & 77.2 & $0.218 \pm 0.016$ & $0.342 \pm 0.022$ & $23.88-56.47$ & 44.77 \\
\hline ISSR & 91.5 & $0.238 \pm 0.012$ & $0.380 \pm 0.016$ & $42.86-72.73$ & 59.69 \\
\hline RGAP & 69.1 & $0.171 \pm 0.020$ & $0.272 \pm 0.027$ & $18.75-50.00$ & 35.03 \\
\hline LP-PCR & 73.3 & $0.221 \pm 0.021$ & $0.341 \pm 0.030$ & $26.00-56.14$ & 40.14 \\
\hline IRAP & 69.6 & $0.169 \pm 0.016$ & $0.273 \pm 0.023$ & $25.00-46.67$ & 36.40 \\
\hline Total data & 78.4 & $0.208 \pm 0.007$ & $0.330 \pm 0.010$ & $34.31-52.77$ & 45.13 \\
\hline
\end{tabular}

fact that conservative plant genome sequences with significant similarity even among the remote species were used for their development.

For REMAP-analysis 20 combinations from five ISSR- and four IRAP-primers were used, five of which yielded clear reproducible patterns with sufficient number of fragments to be potentially suitable for further work (data are not presented). However, the REMAPanalysis with the above combinations of primers almost failed to provide the additional bands as compared with the IRAP-PCR and therefore its further employment was assumed unreasonable.

After primary screening we performed the additional selection of primers, this time guided by the primer ability to uncover polymorphism in the group of eleven I. pumila plants. The monomorphic primers were discarded as non-informative. The names and nucleotide sequences of the chosen primers are presented in Table 1.

Characteristics of individual primers products amplified for tested plant sample are listed in Table 1, while Table 2 presents summarized results for different types of PCR-based markers. An important indicator of the method informativeness is the number of amplicons per primer. An advantage is thought to be the possibility to generate the greater number of amplicons in one reaction and, hence, information as well, at lesser cost and time. The most efficient were ISSR-markers. Number of scorable bands for each ISSR-primer varied from 8 to 37 (Table 1) with an average of 20.5 bands per primer (Table 2). High average number of amplicons per primer was also demonstrated by LP-PCR-markers (Table 2), but distinctions between individual primers by the number of products were much lesser (Table 1). These two primer types also show the highest average number of polymorphic amplicons per primer (Table 2).

To get one more measure of efficiency for population-genetic analysis for each marker system we calculated resolving power ( $\mathrm{Rp})$, which characterizes the ability to distinguish genotypes of both individual primers and the method at all. A resolving power equals to sum of individual band informativeness and is determined by the number of polymorphic bands and distribution of alleles within the sampled genotypes. Band informativeness increases as the allele frequency approaches to 0.5 . That is, the bands which identify two equivalent subgroups within the group of sampled genotypes exhibit higher informativeness than those present in the unique genotypes. The monomorphic bands have zero informativeness. By the Rp index, ISSR-markers occupy the first place among the marker systems involved (Table 2), particularly due to the high number of polymorphic amplicons (Table 3 ). These are followed by LP-PCR-markers (Table 2). They have lesser number of amplicons per primer, so the main contribution to increased $\mathrm{Rp}$ index is apparently made by the even allele distribution. The least $\mathrm{Rp}$ index is displayed by RGAP-primers (Table 2) that is substantially due to the low number of polymorphic bands per primer.

The Bayesian analysis using Structure software showed the highest likelihood value $(\log \operatorname{Pr}(X \mid K))$ at $K=1$ for RAPD, ISSR, LP-PCR and total data. For the rest marker types, log likelihood scores slightly increased reaching maximum value at $K=2$. For RGAP $\log =-513.3$ and -494.3 ; for IRAP $\log =-658.6$ and -613.2 at $K=1$ and $K=2$, respectively. For both marker types at $K=2$ all individuals in population were admixed with nearly equal genome fractions originated from each of two subpopulations. As this symmetric assignment is unlikely from the biological point 
a

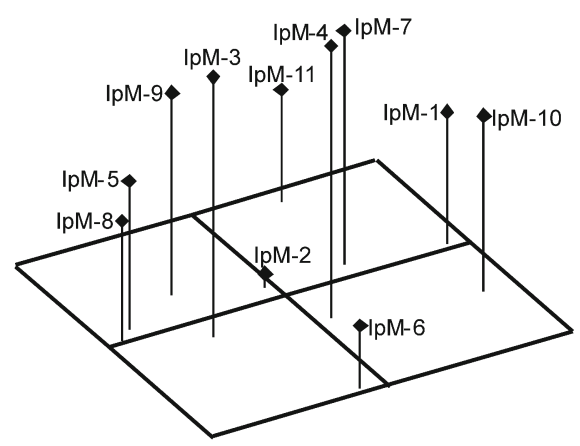

d

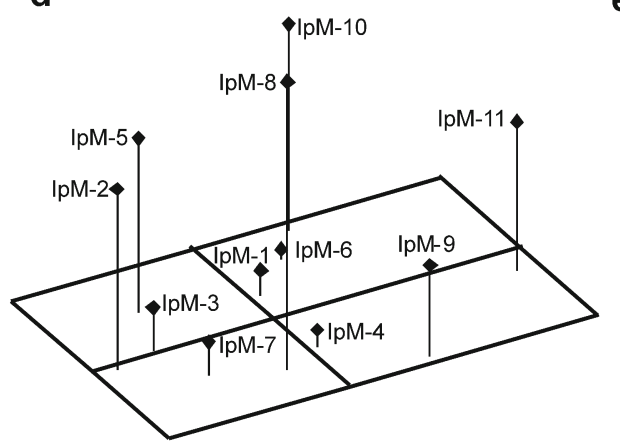

b

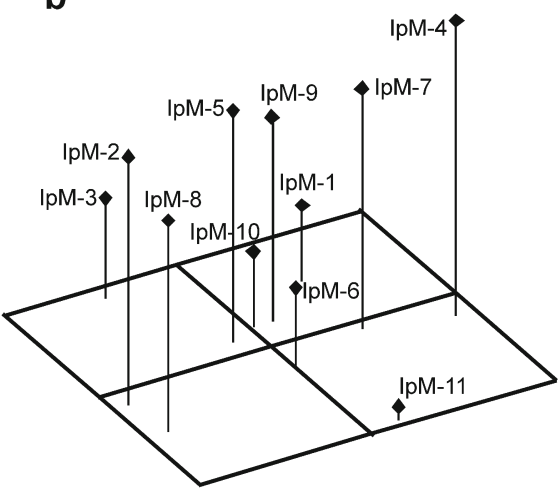

e

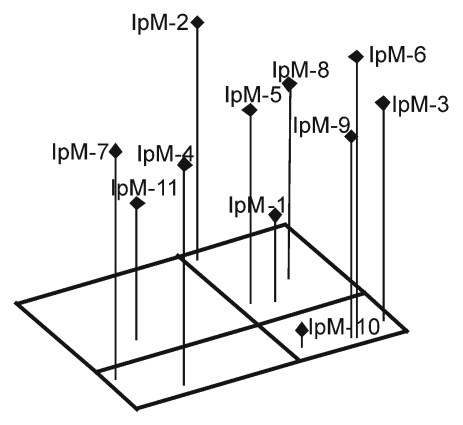

C

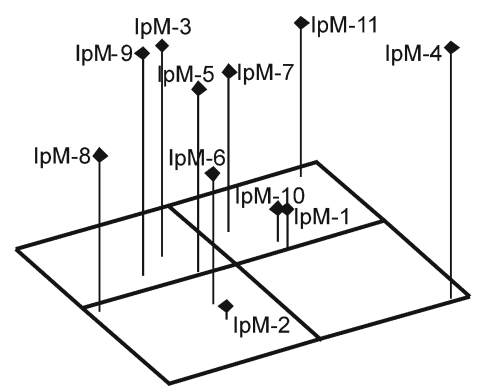

f

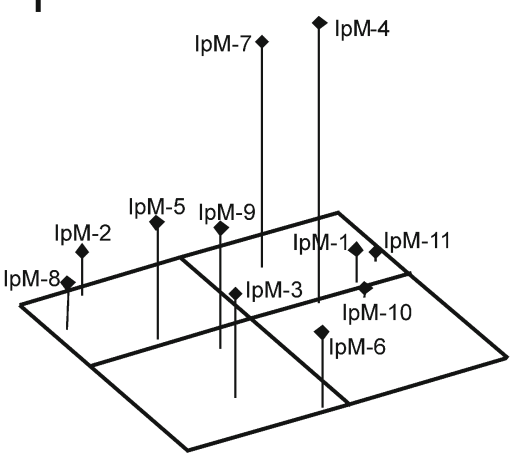

Fig. 1. Three-dimensional plots for the principal coordinate analysis based on Jaccard's genetic distances between plants showing the relationships among $I$. pumila specimens. Plots are presented for the following PCR-based marker systems: a - RAPD, b - ISSR, c RGAP, d - LP-PCR, e - IRAP, f - total data.

of view, we assume that this population structure is not real. Thus, the data of all marker systems suggest that all genomes belonged to one population and there were no admixed individuals.

The indicators of genetic diversity were also calculated. In order of decreasing value of indicators of genetic diversity "the percentage of polymorphic bands" and "the average Jaccard's genetic distance between plants" marker systems may be arranged as follows: ISSR-, RAPD-, LP-PCR-, IRAP- and RGAPmarkers. For ISSR-markers, the percentage of polymorphic bands was 1.3-1.7 times higher than for the others, and the average genetic distance was 1.2-1.3 times higher. For RAPD, LP-PCR, IRAP and RGAPmarkers, values of these indices were somewhat lower than those for the total data (Table 3).

The above-mentioned indicators are calculated on the basis of the number of polymorphic bands and associated with the level of diversity among sampled genotypes. The other two parameters, Nei's gene diversity (expected heterozygosity Ne), and Shannon's index (S) are calculated by the allele frequencies. By these parameters the distribution described above slightly changed due to higher values for LP-PCR-markers and lesser for ISSR-markers (Table 3). Different marker systems were ranked by the value of Nei's gene diversity (expected heterozygosity $\mathrm{He}$ ) and the Shannon's index $(S)$ values as follows: ISSR $>$ RAPD $\approx$ LP$\mathrm{PCR}>\mathrm{RGAP} \approx \mathrm{IRAP}$, with the highest and the lowest values differing 1.4 times.
To provide spatial representation of genetic associations among individual plants, a principal coordinate analysis (PCoA) was carried out based on the Jaccard's distance matrix. The arrangement of the objects on the PCoA plots constructed on the basis of both the data of individual marker systems and summarized data differed from each other (Fig. 1). There was also no distinct grouping pattern, although maximal and minimal genetic distances between individuals calculated from the data of particular marker system differed approximately twice. That may be indicative of the uniform distribution of genetic variation within the sampled group. Mantel test revealed significant positive correlation between the matrices of genetic distances generated by the data of almost all marker systems (Table 4). The strongest correlation was found between RGAPand IRAP-markers $(r=0.452, p=0.01)$ and between RGAP and ISSR $(r=0.430, p=0.01)$, while LP-PCR markers showed significant correlation (at $p<0.05$ ) only with ISSR-markers.

The cluster analyses (Fig. 2) yielded a picture similar to the one given by the principal coordinate analysis showing distinctions of clustering by different markers and summarized data and absence of strong clusters. Comparison of PCoA and dendrogram groupings revealed generally similar but not identical patterns. Bootstrap support values were low for the most branches of consensus NJ trees constructed for individual markers, however their values greatly increased and became significant for summarized data. 
a

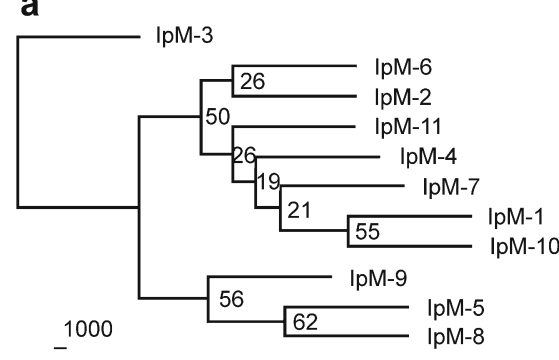

d

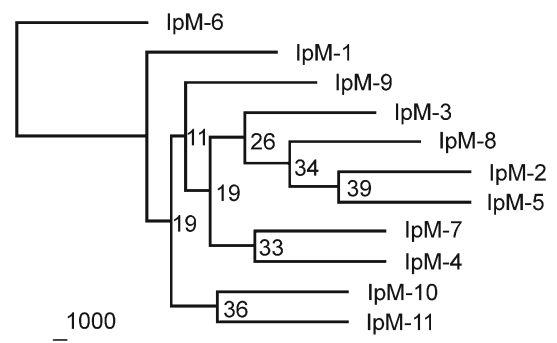

b

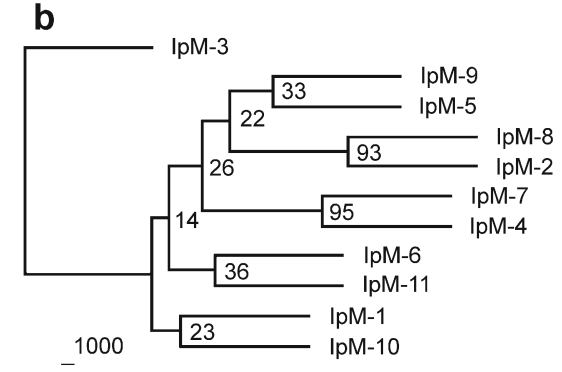

e

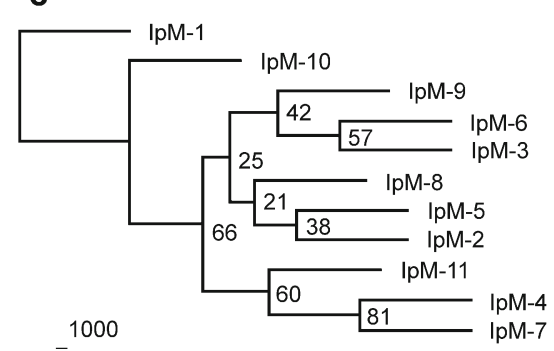

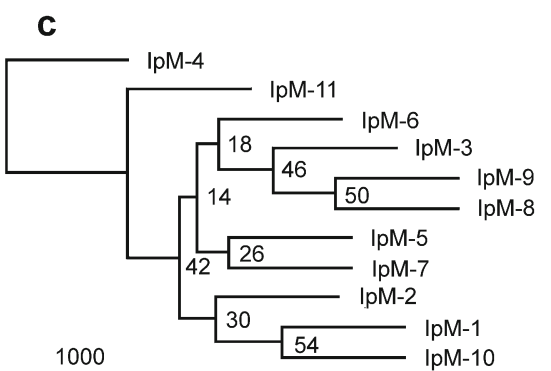

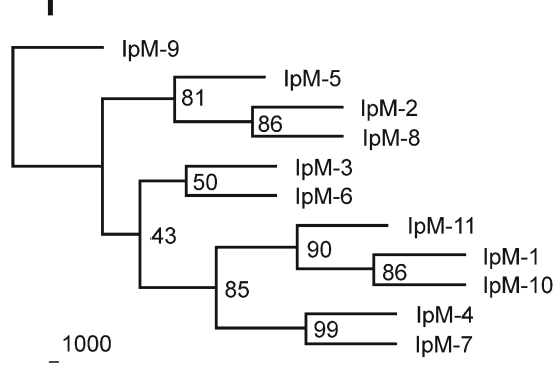

Fig. 2. Extended majority rule consensus NJ trees based on Jaccard's genetic distances between I. pumila plants. Trees constructed using the data of individual PCR-based marker systems are given: a - RAPD, b - ISSR, c - RGAP, d - LP-PCR, e - IRAP, f - total data. The trees branches lengths correspond to the number of times that each group appeared in the input trees. Bootstrap support values obtained for 10000 replicates are indicated in percentages.

Objects position in the PCoA plots and dendrograms of genetic similarity (Figs 1,2) constructed for each marker type as well as for the total data, didn't correspond to their arrangement at the collection area. Generally, spatially more remote samples clustered together and, vice versa, plants growing nearby found themselves in various clusters of the dendrogram. Mantel test with 999 permutations showed the significant correlation $(0.407, p=0.04)$ between the matrix of distances between the plants and matrix of genetic distances generated by the total data, thus suggesting the positive relationship between genetic similarity of the plants and their spatial arrangement.

\section{Discussion}

The effectiveness of PCR-based markers application for population-genetic analysis is mainly determined by the ability to differentiate genotypes. Our findings indicate that the highest level of polymorphism within sampled I. pumila plants was displayed by ISSR-markers $\left(\mathrm{P}=91.5 \%, \mathrm{He}=0.238, \mathrm{~S}=0.380, \mathrm{D}_{\mathrm{j}}=59.69\right)(\mathrm{Ta}-$ ble 3 ). This can be ascribed to their relation to microsatellite regions, which in general have higher rate of mutation compared to the average for the genome. These were followed by RAPD-primers $(\mathrm{P}=77.2 \%$, $\left.\mathrm{He}=0.218, \mathrm{~S}=0.342, \mathrm{D}_{\mathrm{j}}=44.77\right)$, among the amplification products of which non-coding areas predominate, showing high level of mutations as well. Literature data comparing these two types of markers are ambiguous. Some of the works, as in our case, claim that ISSR-analysis is more effective for uncovering polymorphism (Fernandez et al. 2002; Marotti et al. 2007; Behera et al. 2008; Mahar et al. 2011; Gorji et al. 2011; Ding et al. 2009). Furthermore, sometimes the differ- ence is substantial, for example, by the data of Behera et al. (2008) proportion of polymorphic bands generated by these two techniques for bitter gourd ( $\mathrm{Mo}$ mordica charantia L.) differs two-fold and makes up $36.5 \%$ for RAPD- and $74.7 \%$ for ISSR-markers. In some studies these markers show very close results, for example $85.4 \%$ and $85.2 \%$ polymorphic fragments, respectively (Liu et al. 2008). There are also enough works suggesting that RAPD-PCR exceeds ISSR-PCR by the ability to reveal polymorphism (Venkatachalam et al. 2008; Farajpour et al. 2011, Lalhruaitluanga \& Prasad 2009; Arif et al. 2009; Gupta et al. 2008; Mishra 2009; Xavier et al. 2011; Biswas et al. 2010). It seems possible that differences in the effectiveness of various marker systems are related to differences in genome structure of species under study, namely to proportion of coding and non-coding sequences within the genome.

The rest three studied types of markers showed lower polymorphism in the sampled I. pumila plants with IRAP and RGAP being the least effective (Table 3). Literature data on relative effectiveness of these markers are contradictory as well. For Citrus species IRAP-markers somewhat yielded to RAPD- and ISSRmarkers by the level of detected variation: the proportion of polymorphic bands constituted $82.4 \%, 92.1 \%$ and $84.9 \%$, respectively, while the expected heterozygosity $-0.24,0.29$ and 0.22 (Biswas et al. 2010). IRAPand RAPD-PCR showed approximately equal efficiency for differentiating the Eryngium species (Jawdat et al. 2010), while IRAP-markers proved to be more effective than ISSR for polymorphism detection in tobacco (Nicotiana tabacum L.) and grapevine (Vitis vinifera L.) (Tao et al. 2009; D'Onofrio et al. 2010). RGAPand RAPD-markers revealed almost identical level of 
Table 4. Correlation between the matrices of genetic distances derived from different marker systems, as assessed by the Mantel test (Mantel, 1967) with 999 permutations.

\begin{tabular}{|c|c|c|c|c|c|}
\hline & RAPD & ISSR & RGAP & LP-PCR & IRAP \\
\hline RAPD & - & & & & \\
\hline ISSR & $0.367(\mathrm{p}=0.007)$ & - & & & \\
\hline RGAP & $0.381(\mathrm{p}=0.011)$ & $0.430(\mathrm{p}=0.01)$ & - & & \\
\hline LP-PCR & $0.251(\mathrm{p}=0.057)$ & $0.338(\mathrm{p}=0.04)$ & $0.111(\mathrm{p}=0.34)$ & - & \\
\hline IRAP & $0.358(\mathrm{p}=0.012)$ & $0.399(\mathrm{p}=0.02)$ & $0.452(\mathrm{p}=0.01)$ & $0.338(\mathrm{p}=0.05)$ & - \\
\hline Total data & $0.709(\mathrm{p}=0.001)$ & $0.798(\mathrm{p}=0.01)$ & $0.674(\mathrm{p}=0.01)$ & $0.538(\mathrm{p}=0.01)$ & $0.691(\mathrm{p}=0.01)$ \\
\hline
\end{tabular}

polymorphism in population analysis of Pinus oocarpa (Díaz \& Ferrer 2003).

One more additional parameter to estimate the efficiency of various marker systems in the analysis of I. pumila provides the resolving power $(\mathrm{Rp})$, which strongly correlates with genotype discrimination (Prevost \& Wilkinson 1999; Tiwari et al. 2009; Fernandez et al. 2002; Marotti et al. 2007; Liu et al. 2008). In case of $I$. pumila, the highest average resolving power was demonstrated by ISSR- and LP-PCR-markers (8.66 and 6.96 , respectively), the rest of the techniques showed lower values: $\mathrm{RAPD}-4.98$, IRAP -4.31 , RGAP -3.76 (Table 2). Similarly to our results, the studies on genetic diversity in plants showed that $\mathrm{Rp}$ values for ISSRmarkers were generally somewhat higher than those for RAPD-markers (Behera et al. 2008; Kayis et al. 2010; Xavier et al. 2011; Acharya et al. 2011). The difference was especially considerable in studies of Hordeum vulgare cultivars, where average resolving power of ISSRand RAPD-primers made up 9.79 and 3.85, respectively (Fernandez et al. 2002). Sometimes the values were almost identical; thus, means of Rp for RAPD-primers in the work of Liu et al. (2008) constituted 4.06, and that for ISSR-primers - 3.98. However, in some cases ISSR yielded to RAPD by this parameter (Venkatachalam et al. 2008).

Range of $\mathrm{Rp}$ variation for individual primers of the same type selected for study of genetic diversity in $I$. pumila proved to be sufficiently high (Table 1). Literature data analysis also suggests the considerable distinctions in resolving power between the primers of the same type. For example, in the studies on banana cultivars (Musa L.) Rp of RAPD-primers varied from 0.66 to 8.19 (average value 3.04), while that of ISSR-primers - from 1.24 to 3.33 (on average 2.56) (Venkatachalam et al. 2008). This, most likely, may reflect different informativeness of individual primers and indicate the need for thorough primary screening even among the primers of potentially efficient type.

NJ trees and PCoA plots of I. pumila samples based on genetic distances differed for each marker system (Fig. 1). Correlation between matrices of genetic distances generated by the data of various marker types in Mantel test (Mantel, 1967) ranged from 0.111 to 0.452 (Table 4). Differences between the matrices of genetic distances generated by different marker systems do occur in studies of genetic polymorphism rather frequently. At the same time some of the studies found strong correlation between the genetic distances determined by various types of markers. This contradiction could be explained by insufficient or unequal number of different marker types that results in non-uniform coverage of genome. Another possibility is the difference in patterns of nucleotide sequence variation in genomic regions targeted at by different markers. Putative hidden polymorphism of amplicons similar by size in different individuals may also lead to wrong results when calculating genetic relationships (Fernandez et al. 2002).

All this indicates a need for rational increase in markers number for adequate estimation of genetic relationships together with simultaneous usage of various marker systems to cover the whole genome, as many authors emphasize (Fernandez et al. 2002; Gupta et al. 2008; Biswas et al. 2010; Gorji et al. 2011). For example, Thimmappaiah et al. (2009) analyzed cashew germplasm with ISSR- and RAPD-markers separately and simultaneously, and found that combining the data from two marker systems ensure more efficient genotypes differentiation. However, a successful program for studying and conserving a biodiversity shouldn't be based exclusively on findings of RAPD and ISSRanalyses, since these markers are mainly targeting noncoding regions and may not correlate with adaptive characters. These should be combined with investigations of the adaptive genetic variation that may be determined with greater certainty by the variation in coding sequences (Xavier et al. 2011).

Thus, as a result of the study, the effective molecular markers of various types have been selected that may be used for further studies of I. pumila genetic polymorphism. Although our data show that ISSR, RAPD and LP-PCR-markers proved to be more effective in some aspects, high levels of polymorphism were observed for all selected markers regardless of the type. It means that all of them may be useful in estimating the I. pumila genetic diversity and characterizing the species germplasm. Simultaneous use of all marker systems studied would allow deriving the most complete and comprehensive characteristics of variation in different genome regions.

\section{Acknowledgements}

The authors are grateful to Dr. Ivan Parnikoza (Institute of Molecular Biology and Genetics, NASU) for collecting and providing plants of I. pumila for the research. We also thank Volodymyr Adonin (Institute of Molecular Biology and Genetics, NASU) for help with English translation. This research was financially supported by Targeted interdisciplinary programme of scientific research "Fundamentals of 
molecular and cellular biotechnology", National Academy of Sciences of Ukraine.

\section{References}

Acharya L., Mukherjee A.K. \& Panda P.Ch. 2011. Separation of the genera in the subtribe Cassiinae (Leguminosae: Caesalpinioidae) using molecular markers. Acta Bot. Brasil 25: 223-233.

Arif M., Zaidi N.W., Singh Y.P., Haq Q.M.R. \& Singh U.S. 2009. A comparative analysis of ISSR and RAPD markers for study of genetic diversity in shisham (Dalbergia sissoo). Plant Mol. Biol. Rep. 27: 488-495.

Behera T.K., Gaikward A.B., Singh A.K. \& Staub J.E. 2008. Relative efficiency of DNA markers (RAPD, ISSR and AFLP) in detecting genetic diversity of bitter gourd (Momordica charantia L.). J. Sci. Food Agric. 88: 733-737.

Biswas M.K., Xu Q. \& Deng X. 2010. Utility of RAPD, ISSR, IRAP and REMAP markers for the genetic analysis of Citrus spp. Sci. Hortic.124: 254-261.

Chuanliang D., Jian Zh., Longdou L., Wujun G. \& Shufen L. 2006. Study on germplasmic resources of Lycoris longituba using RAPD and ISSR. Analele Universitatii „Alexandru Ioan Cuza", Seria Genetica si Biologie Moleculara 7: 111120.

D'Onofrio C., De Lorenzis G., Giordani T., Natali L., Cavallini A. \& Scalabrelli G. 2010. Retrotransposon-based molecular markers for grapevine species and cultivars identification. Tree Genet. Genomes 6: 451-466.

Díaz V. \& Ferrer E. 2003. Genetic variation of populations of Pinus oocarpa revealed by resistance gene analog polymorphism (RGAP). Genome 46: 404-410.

Ding G., Li X., Ding X. \& Qian L. 2009. Genetic diversity across natural populations of Dendrobium officinale, the endangered medicinal herb endemic to China, revealed by ISSR and RAPD markers. Russ. J. Genet. 45: 327-334.

Dong P., Wei Y.M., Chen G.Y., Li W., Nevo E. \& Zheng Y.L. 2009. Resistance gene analog polymorphisms (RGAPs) in wild emmer wheat (Triticum dicoccoides) and their ecological associations. Genet. Resour. Crop Evol. 56: 121-136.

Doyle J.J. \& Doyle J.L. 1987. A rapid DNA isolation procedure for small quantities of fresh leaf tissue. Phytochem Bull. 19: $11-15$.

Farajpour M., Ebrahimi M., Amiri R., Noori S.A.S., Sanjari S. \& Golzari R. 2011. Study of genetic variation in yarrow using inter-simple sequence repeat (ISSR) and random amplified polymorphic DNA (RAPD) markers. Afr. J. Biotechnol. 10: 11137-11141.

Fernandez M.E., Figueras A.M. \& Benito C. 2002. The use of ISSR and RAPD markers for detecting DNA polymorphism, genotype identification and genetic diversity among barley cultivars with known origin. Theor. Appl. Genet. 104: 845851.

Gorji A.M., Poczai P., Polgar Z. \& Taller J. 2011. Efficiency of arbitrarily amplified dominant markers (SCOT, ISSR and RAPD) for diagnostic fingerprinting in tetraploid potato. Am. J. Potato Res. 88: 226-237.

Gupta P.K. \& Rustgi S. 2004. Molecular markers from the transcribed/expressed region of the genome in higher plants. Funct Integr. Genomics 4: 139-162.

Gupta Sh., Srivastava M., Mishra G.P., Naik P.K., Chauhan R.S., Tiwari S.K., Kumar M. \& Singh R. 2008. Analogy of ISSR and RAPD markers for comparative analysis of genetic diversity among different Jatropha curcas genotypes. Afr. J. Biotechnol. 7: 4230-4243.

Jawdat D., Al-Faoury H., Ayyoubi Z. \& Al-Safadi B. 2010. Molecular and ecological study of Eryngium species in Syria. Biologia 65: 796-804.

Kalendar R. 2011. The use of retrotransposon-based molecular markers to analyze genetic diversity. Ratar. Povrt. / Field Veg. Crop Res. 48: 261-274.

Kalendar R.N. \& Glazko V.I. 2002. Types of molecular-genetic markers and their application. Physiol. Biochem. Cult. Plants 34: $279-296$.
Kayis S.A., Hakki E.E. \& Pinarkara E. 2010. Comparison of effectiveness of ISSR and RAPD markers in genetic characterization of seized marijuana (Cannabis sativa L.) in Turkey. Afr. J. Agr. Res. 5: 2925-2933.

Lalhruaitluanga H. \& Prasad M.N.V. 2009. Comparative results of RAPD and ISSR markers for genetic diversity assessment in Melocanna baccifera Roxb. growing in Mizoram State of India. Afr. J. Biotechnol. 8: 6053-6062.

Liu L.W., Zhao L.P., Gong Y.Q., Wang M.X., Chen L.M., Yang J.L., Wang Y., Yu F.M. \& Wang L.Zh. 2008. DNA fingerprinting and genetic diversity analysis of late-bolting radish cultivars with RAPD, ISSR and SRAP markers. Sci. Hortic. 116: $240-247$.

Liviero L., Maestri E., Gulli M., Nevo E. \& Marmiroli N. 2002. Ecogeographic adaptation and genetic variation in wild barley, application of molecular markers targeted to environmentally regulated genes. Genet. Resour. Crop. Evol. 49: 133144.

Mahar K.S., Rana T.S., Ranade S.A. \& Meena B. 2011. Genetic variability and population structure in Sapindus emarginatus Vahl from India. Gene 485: 32-39.

Mantel N. 1967. The detection of disease clustering and a generalized regression approach. Cancer Res. 27: 209-220.

Marotti I., Bonetti A., Minelli M., Catizone P. \& Dinelli G. 2007. Characterization of some Italian common bean (Phaseolus vulgaris L.) landraces by RAPD, semi-random and ISSR molecular markers. Genet Resour. Crop Evol. 54: 175-188.

Mishra G.P. 2009. Correspondence of DNA markers for genetic diversity studies among different apricot genotypes from cold arid deserts of Ladakh. DRDO Science Spectrum 151-156.

Mondini L., Noorani A. \& Pagnotta M.A. 2009. Assessing plant genetic diversity by molecular tools. Diversity 1: 19-35.

Parnikoza I.Yu., Troicka T.B., Troickij M.A. \& Kunakh V.A. 2011. Iris pumila L. in Ukraine, pp. 105-110. In: Novikov V.S. (ed.), Proceedings of the II Moscow international symposium "Iris-2011", Botanical Garden of the Lomonosov Moscow State University, Moscow.

Peakall R. \& Smouse P.E. 2006. GENALEX 6: genetic analysis in Excel. Population genetic software for teaching and research. Mol. Ecol. Notes 6: 288-295.

Penner G.A. 1996. RAPD analysis of plant genomes, pp. 251268. In: Jauhar P.P. (ed.), Methods of Genome Analysis in Plants, CRC Press, Boca Raton.

Prevost A. \& Wilkinson M.J. 1999. A new system of comparing PCR primers applied to ISSR fingerprinting of potato cultivars. Theor. Appl. Genet 98: 107-112.

Schluter P.M. \& Harris S.A. 2006. Analysis of multilocus fingerprinting data sets containing missing data. Mol. Ecol. Notes 6: $569-572$.

Sikura I.I. \& Shysha E.N. 2010. Genus Iris L. (Iridaceae). Znaniya Ukrainy, Kiev, 196 pp.

Tao A.F., Liu Zh.H., Qi J.M., Zhou D.X., Wang T. \& Chen Sh.H. 2009. Comparison and analysis of IRAP and ISSR molecular methods used for assessment of genetic diversity in tobacco. J. Wuhan Bot. Res. 27: 589-594.

Thimmappaiah, Santhosh W.G., Shobha D. \& Melwyn G.S. 2009. Assessment of genetic diversity in cashew germplasm using RAPD and ISSR markers. Sci. Hortic. 120: 411-417.

Tiwari Sh.K., Karihaloo J.L., Hameed N. \& Gaikwad A.B. 2009. Molecular characterization of brinjal (Solanum melongena L.) cultivars using RAPD and ISSR markers. J. Plant Biochem. Biotechnol. 18: 189-195.

Venkatachalam L., Sreedhar R.V. \& Bhagyalakshmi N. 2008. The use of genetic markers for detecting DNA polymorphism, genotype identification and phylogenetic relationships among banana cultivars. Mol. Phylogenet. Evol. 47: 974-985.

Xavier J.R., Kumar J. \& Srivastava R.B. 2011. Characterization of genetic structure of alfalfa (Medicago sp.) from transHimalaya using RAPD and ISSR markers. Afr. J. Biotechnol. 10: $8176-8187$.

Received November 11, 2012 Accepted April 18, 2013 